\title{
THERMAL AND STRUCTURAL ANALYSIS OF RCC DOUBLE-CURVATURE ARCH DAM
}

\author{
Aeid Ali ABDULRAZEG ${ }^{\mathrm{a}}$, Jamaloddin NOORZAEI ${ }^{\mathrm{b}, \mathrm{c}}$, Mohamed Saleh JAAFAR $^{\mathrm{b}}$, \\ Parvin KHANEHZAEI ${ }^{\mathrm{b}}$, Thamer Ahmed MOHAMED ${ }^{\mathrm{b}}$ \\ ${ }^{a}$ Civil Engineering Department, Omar Al Mukhtar University, El-Beida, Libya \\ ${ }^{b}$ Civil Engineering Department Universiti Putra Malaysia, 43400 UPM-Serdang, Malaysia \\ 'Institute of advance Technology, Universiti Putra Malaysia,43400 UPM- Serdang, Malaysia
}

Received 08 Dec 2011; accepted 20 Feb 2012

\begin{abstract}
This paper focuses on the development, verification and application of a three-dimensional finite element code for coupled thermal and structural analysis of roller compacted concrete arch dams. The Karun III Arch dam located on Karun River, Iran, which was originally designed as a conventional concrete arch dam, has been taken for the purpose of verification of the finite element code. In this study, RCC technology has been ascertained as an alternative method to reduce the cost of the project and make it competitive. A numerical procedure to simulate the construction process of RCC arch dams is presented. It takes into account the more relevant features of the behavior of concrete such as hydration, ageing and creep. A viscoelastic model, including ageing effects and thermal dependent properties is adopted for the concrete. The different isothermal temperature influence on creep and elastic modulus is taken into account by the maturity concept. Crack index is used to assess the occurrence of crack and evaluate the level of safety of the dam. This study demonstrates that, high tensile stress concentration has been observed at the lower part and the abutment boundaries of the dam.
\end{abstract}

Keywords: RCC, arch, thermal stress, creep, mechanical behavior, crack safety factor, finite element method.

Reference to this paper should be made as follows: Abdulrazeg, A. A.; Noorzaei, J.; Jaafar, M. S.; Khanehzaei, P.; Mohamed, T. A. 2014. Thermal and structural analysis of RCC double-curvature arch dam, Journal of Civil Engineering and Management 20(3): 434-445. http://dx.doi.org/10.3846/13923730.2013.801897

\section{Introduction}

The RCC technology has being applied in gravity arch dams in the late of 1980s. The first RCC arch dam was constructed in the world is Kenllpoort dam, which was completed in S. Africa in 1988 (Qiuhua 2003). Up to the end of 2003, the number of RCC arch dams completed or under construction is 14 . The construction technology of a RCC arch dam is very similar to that of a RCC gravity dam. The main differences between arch RCC dam and gravity RCC dam are that arch dam has a wider surface and lesser thickness, accordingly different thermal and stress response.

Xie et al. (2005) and Zhang et al. (2009) used a three-dimensional finite element relocating mesh method to simulate construction process and compute temperature field. In their work, many factors have also been considered, such as thermal adiabatic rise of temperature with age, the process of placement by layer, creep, work suspension in summer and the change of air temperature. However, the studies were limited for thermal analysis only. In addition, further studies to select the proper relocating age of concrete are essential. Penghui et al. (2007) determined creep values for thermal analysis of Dahuashui RCC arch dam, applied time and stress dependent coefficient, in a multi-term expression, whereby certain constants were apparently derived through experimental study to an accuracy of six decimal places. In the presented work, the variation of the RCC mechanical properties with time has not been considered and fixed values were used during the analysis.

Shuping et al. (1999) performed an emulation analysis of two RCC arch dams using three dimensional finite elements. It has been found that, the thermal stresses were too high for the construction plan without contraction joints. However, the authors ignored the effect of dam foundation interaction. In 2003, a similar study was conducted by Nilipour (2003). It was concluded that, at the same elevation higher temperature rise was experienced in the core of the dam in applying conventional method as compared with RCC method. However, higher tensile stress occurs in the model using conventional method in the early age of concrete. Whereas, maximum tensile stress in RCC model occurs later due to operation loads comparatively with a lower value, hence postcooling is not necessary in RCC construction method. However, in these investigations a simplified relation for stress-strain relationship has been used which will overestimate the stress of the dam (Crichton et al. 1999). 
It is of particular significance to observe that, most of the studies that address the stress analysis of RCC dams have considered the time dependent deformation such as creep very approximately or neglected it all together (Araujo, Awruch 1998; Agullo, Aguado 1995; Saetta et al. 1995; Malkawi et al. 2003; Noorzaei et al. 2006; Zhiqi 2007). However, creep has a significant influence on the stress values of the concrete blocks, especially in early ages (Santurjian, Kolarow 1995). Moreover, there was a concern that RCC acts in the same manner as conventional concrete and various models developed for the conventional concrete are applied for RCC without any form of verification. Furthermore, the material laws for concrete, mainly based on the age of concrete and very limited study, considered the temperature effect on the mechanical properties of the concrete (Luna, Wu 2000; Cervera et al. 2000).

Consistent cracking criterion is also necessary for an exact evaluation of the dam behavior. Most of the previous researchers who investigated dam concrete mainly focused on the uniaxial compressive strength and tensile strength, so their studies did not provide information on the behavior of dam concrete under bi-axial or tri-axial stress states (Wang, Song 2008).

\section{Motivation of the present work}

The present investigation is a continuation of the authors' previous work (Bayagoob et al. 2010) and presenting a numerical implementation using three-dimensional finite element method to simulate the construction process of RCC arch dams. The primary objectives of the present research work:

- This paper presents a new comprehensive numerical procedure to simulate the construction process of arch RCC dams. It takes into account the more relevant features of the behavior of concrete such as hydration, ageing, thermal and creep effect;

- To apply the proposed model to an actual arch RCC dam to demonstrate the efficiency of the model.

\section{Computation of thermal field}

The Numerical solution scheme used in this study is based on the Taylor-Galerkin approach. Upon applying this approach, the following system of differential equations is obtained (Bayagoob et al. 2010):

$$
\left[K_{t}\right]^{(e)}\{T\}^{(e)}-[C]^{e}\left\{\frac{\partial T}{\partial t}\right\}^{(e)}=\{F\}^{(e)},
$$

where: $[C]^{e}$ is the capacitance matrix; $\left[K_{t}\right]$ is the heat stiffness matrix; $\{F\}$ is the total load heat vector due to hydration and convection actions.

The finite difference approximation was used to solve Eqn (1) in the time domain numerically. This solution (after assembly of the stiffness matrices) is given by (Sergerlind 1984):

$$
\begin{aligned}
& \left([C]+\theta \Delta t\left[K_{t}\right]\right)\{T\}_{b}= \\
& \left([C]+\theta \Delta t\left[K_{t}\right]\right)\{T\}_{a}+\Delta t\left((1-\theta)\left\{F_{t}\right\}_{a}+\theta\left\{F_{t}\right\}_{b}\right),
\end{aligned}
$$

where: $\{T\}_{b}$ and $\left\{\mathrm{F}_{\mathrm{t}}\right\}_{\mathrm{b}}$ are $\{\mathrm{T}\}$ and $\left\{\mathrm{F}_{\mathrm{t}}\right\}$ at time (b) and $\{T\}_{a}$ and $\left\{F_{t}\right\}_{a}$ are $\{\mathrm{T}\}$ and $\left\{\mathrm{F}_{\mathrm{t}}\right\}$ at time (a); $\theta$ is a scalar $(0 \leq \theta \leq 1)$ which is equal to $2 / 3$ in the Galerkin method. Then Eqn (2) takes the following general form:

$$
\left[A_{G}\right]\{\Delta T\}=\left[F_{G}\right] \text {, }
$$

where:

$$
\left[A_{G}\right]=\frac{1}{\Delta t}[C]+\frac{2}{3}\left[K_{t}\right]
$$

and

$$
\left\{F_{G}\right\}=\frac{1}{2}\left(\left\{F_{t}\right\}_{a}+2\left\{F_{t}\right\}_{b}-3\left[K_{t}\right]\{T\}_{a}\right),
$$

where: $\{\Delta T\}$ represents the temperature changes at the nodal points with respect to time $\Delta t$ which is used for evaluation of temperatures at the new time stage using the following expression:

$$
\{T\}_{b}=\{T\}_{a}+\frac{2}{3}\{\Delta T\}
$$

\section{Constitutive theories for aging viscoelastic materials}

Time dependent behavior of concrete is described by the theory of viscoelasticity for aging materials. The sum of elastic $\left\{\varepsilon_{e}\right\}$ and creep $\left\{\varepsilon_{c}\right\}$ strain is replaced by the viscoelastic strain $\left\{\varepsilon_{v e}\right\}$ as follows:

$$
\left\{\varepsilon_{v e}\right\}=\left\{\varepsilon_{e}\right\}+\left\{\varepsilon_{c}\right\} .
$$

According to the viscoelastic theory, the strain at time $t$ caused by constant stress $\sigma$ applied at time $\tau$ is given by:

$$
\varepsilon(t, \tau)=J(t, \tau) \sigma .
$$

According to Boltzmann's principal of superposition of strains, which was modified by Neville (Neville et al. 1983) to include the effect of aging of concrete, the summation of the strain history due to all stress increments $\Delta \sigma(\tau)$ before time $(t)$ is expressed as (Atrushi 2003):

$$
\varepsilon(t)=\sum_{\tau=t_{0}}^{t} J(t, \tau) \Delta \sigma(\tau),
$$

where: $t$ is current time (measured from casting of concrete); $\tau$ is concrete age at loading; $\Delta \sigma(\tau)$ is stress increment applied at $\tau ; \varepsilon(t)$ is total strain and $J(t, \tau)$ is creep compliance. 
If the stress varies continuously, Eqn (7) could be expressed as (Du, Liu 1994):

$$
\varepsilon(t)=\int_{\tau}^{t} J(t, \tau) d \sigma(\tau)+\varepsilon_{o}(t) .
$$

\subsection{Creep compliance of RCC material}

The exponential model of creep has been attractive from the computation point of view, because it can avoid storing the whole stress history and made the implementation feasible comparing with other models (Abdulrazeg et al. 2010).

The creep functions may be expressed with Dirichlet series (Wu, Luna 2001) as:

$$
J(t, \tau)=\sum_{\gamma=1}^{M} \frac{1}{\mu_{\gamma}(\tau)}\left[1-e^{y_{\gamma}(\tau)-y_{\lambda}(t)}\right],
$$

where: $J(t, \tau)$ is creep functions; $\mu_{\gamma}(\tau)$ is function of one variable, called the reduced times; $\tau$ is the loading age in days, $y_{\gamma}(\tau)$ is experimental function.

Neglecting temperature effects, a specific form of the compliance function is often used (Du, Liu 1994):

$$
J(t, \tau)=C(t, \tau)+\frac{1}{E(t)},
$$

where $C(t, \tau)$ is creep compliance, it can be expressed as,

$$
\begin{gathered}
C(t, \tau)=\sum_{\gamma=1}^{3} \phi_{\gamma}(\tau)\left[1-e^{-S_{\gamma}(t-\tau)}\right] \\
\varphi_{1}=\alpha_{1}+\beta_{1} \tau^{-\delta_{1}}, \quad \varphi_{2}=\alpha_{2}+\beta_{2} \tau^{-\delta_{2}}, \quad \varphi_{3}=D e^{-S_{3} \tau},
\end{gathered}
$$

where $\alpha_{\gamma}, \beta_{\gamma}, \delta_{\gamma}, D, S_{\gamma}$ are constants determined from the experimental data.

$E(t)$ is elastic modulus, and the model which developed by (Conrad et al. 2003), has been used in this study. This model expresses the variation of the elastic modulus of RCC material with time:

$$
E(t)=E_{c} e^{a \tau^{b}},
$$

where $E_{c}$ is the final elastic modulus, $a$ and $b$ are model parameters.

\section{Proposed models of creep and elastic with temperature effect}

Bazant introduced the concept of the degree of hydration to include the temperature influence (Bazant et al. 2004). Term of equivalent age $\tau_{e}$, which represents the hydration period for which the same degree of hydration is reached at a current temperature as that one reached during the actual time $(t)$ at a reference temperature. The concrete age, $\tau$ will be replaced by equivalent age $\tau_{e}$ in the exponential model Eqn (9):

$$
\tau_{e}=\int_{0}^{\tau} \beta_{\tau}(t) d t,
$$

where $\beta(t)$ is a function of current temperature and expressed as:

$$
\beta_{\tau}(t)=e^{\Pi_{h}\left(\frac{1}{T_{r}}+\frac{1}{T(t)}\right)},
$$

where: $T(t)$ is a current temperature, $T_{r}=20^{\circ} \mathrm{C} ; \Pi_{h}$ is function of hydration degree $=2700 \mathrm{~K}$. To consider the temperature effect on the creep compliance, a function $y_{\gamma}(t)$ is introduced as:

$$
y_{\gamma}(t)=S_{\gamma} \int_{0}^{t} \psi_{T}(t) d t,
$$

where $\psi_{\tau}(t)$ is a function of current temperature and expressed as:

$$
\psi_{\tau}(t)=e^{\Pi_{\alpha}\left(\frac{1}{T_{r}}+\frac{1}{T(t)}\right)},
$$

where $\Pi_{\alpha}$ is function of activation energy of creep $=$ $5000 \mathrm{~K}$.

Using the introduced term of equivalent age $\tau_{e}$, which represents the hydration period, the concrete age, $\tau$ will be replaced with this equivalent age $\tau_{e}$ in the above elastic modulus Eqn (12). So modified model includes the aging and temperature effects on the elastic modulus (Abdulrazeg et al. 2010a).

\section{Creep at variable temperature}

For changing temperature conditions while the concrete is under load, an additional creep component, the so-called transient thermal creep, which develops at the time of a temperature increase, should be considered (Bosnjak 2000). Transient thermal creep is interdependence between temperature response and mechanical response, and based on that the thermal strain rate should be made depending on the current stress state (Thelandersson 1987):

$$
\Delta \varepsilon_{T}=\alpha \Delta T\left(1+\xi \frac{\sigma}{f_{c}}\right),
$$

where: $\Delta \varepsilon_{T}$ is thermal strain increment; $\sigma$ current stress; $f_{c}$ is uniaxial compressive strength at reference temperature; $\Delta T$ is temperature change; $\xi$ model parameter and $\alpha$ coefficient of thermal expansion.

Jonasson (1994) applied Eqn (15) to young concrete and further modified the Eqn (13) and expressed as:

$$
\Delta \varepsilon_{T}=\alpha \Delta T\left(1+\xi \frac{\sigma}{f_{t}} \operatorname{sign} \Delta T\right),
$$

where: $f_{t}$ is the tensile strength at reference temperature and $\xi$ range between $(0.1-0.7)$ the best value for $\xi$ fitted to the test results was 0.27 (Hedlund 1996). 


\section{The formulation of RCC creep with temperature effects}

To predict the response of the concrete in the early period of construction, a step-by-step method is necessary. At the beginning of each time step, deformation due to thermal variation (hydration and environment) and creep during the current time interval are imposed. This imposed incremental strain on any point at $i^{\text {th }}$ time interval is defined as:

$$
\Delta \varepsilon_{n}=\Delta \varepsilon_{n}^{e}+\Delta \varepsilon_{n}^{c}+\Delta \varepsilon_{n}^{T}+\Delta \varepsilon_{n}^{T r c r},
$$

where $\Delta \varepsilon_{n}^{e}, \Delta \varepsilon_{n}^{c}, \Delta \varepsilon_{n}^{T}, \Delta \varepsilon_{n}^{T r c r}$ refer to elastic, creep, temperature and transient thermal creep strain increment column vectors, respectively.

$\mathrm{Wu}$ and Luna 2001 introduced the numerical procedure for creep strain in mass concrete structure with temperature effects by modifying the exponential algorithm for concrete and the final formula for the incremental in strain (Eqn (17)) are presented below.

Let the total time interval $\left[t_{0}, t\right]$ be subdivided into $\mathrm{N}$ steps, for the step $\left[t_{i-1}, t_{i}\right]$, the creep strain increment column vector within step $\left[t_{n-1}, t_{n}\right]$ may be generalized as:

$$
\begin{aligned}
\left\{\Delta \varepsilon^{c}\right\}= & {[Q] \sum_{\gamma=1}^{3}\left[\left(1-e^{-S_{\gamma} \psi_{\tau_{n}} \Delta_{\tau_{n}}}\right)\left\{\omega_{\gamma n}\right\}+\left\{\Delta \sigma_{n}\right\} \phi_{\gamma n} h_{\lambda n}\right]=} \\
& \left\{\eta_{n}\right\}+q_{n}[Q]\left\{\Delta \sigma_{n}\right\},
\end{aligned}
$$

where:

$$
\begin{aligned}
& \left\{\eta_{n}\right\}=\sum_{\gamma=1}^{3}\left[\left(1-e^{-S_{\gamma} \psi_{\tau_{n}} \Delta_{\tau_{n}}}\right)\left\{\omega_{\gamma n}\right\}\right] \\
& \left\{\omega_{\gamma n}\right\}=\left\{\omega_{\gamma n-1}\right\} e^{-S_{\gamma} \psi_{\tau_{n-1}} \Delta_{\tau_{n-1}}}+[Q]\left\{\Delta \sigma_{n-1}\right\} \varphi_{\gamma n-1} f_{\gamma n-1} e^{-Y_{n-1}} ; \\
& q_{n}=\sum_{\gamma=1}^{3} \varphi_{\gamma n} h_{\gamma n} \\
& h_{\gamma n}=1-f_{\gamma n} e^{-Y_{n}} ; \\
& Y_{n}=S_{n} \sum_{j=1}^{n} \psi_{T j} \Delta_{T j} \\
& f_{\gamma n}=\frac{1}{\Delta \tau_{n}} \int_{t_{n-1}}^{t_{n}} e^{y_{s}(\tau)} \text {; } \\
& {[Q]=\left[\begin{array}{cccccc}
1 & -v & -v & 0 & 0 & 0 \\
& 1 & -v & 0 & 0 & 0 \\
& & 1 & 0 & 0 & 0 \\
& & 2(1+v) & 0 & 0 \\
& \text { Sym. } & & & 2(1+v) & 0 \\
& & & & & 2(1+v)
\end{array}\right] \cdot(\mathrm{g}-18)}
\end{aligned}
$$

The corresponding stress increment can be obtained:

$$
\begin{gathered}
\left\{\Delta \sigma_{n}\right\}=\left[D_{n}^{\prime}\right]\left(\left\{\Delta \varepsilon_{n}\right\}-\left\{\eta_{n}\right\}-\left\{\Delta \varepsilon_{n}^{T}\right\}\right) ; \\
{\left[D_{n}^{\prime}\right]=\frac{\left[D_{n}\right]}{\left(1+q_{n} E_{n}\right)},}
\end{gathered}
$$

where: $\left[D_{n}\right]$ is the elastic matrix for plane strain problem at the $n^{\text {th }}$ time interval. The full details of the mathematical derivation are given in the previous work, the authors (Abdulrazeg et al. 2010).

\section{Crack analysis}

The crack development in RCC dam due to deferent loads acting on the dam during the construction or the operation stages such as thermal load, gravity, hydrostatic load and creep, in a given time interval depends on the development of mechanical properties, especially elastic modulus and tensile strength. Making reliable crack prediction assessment involves advanced modelling of the time and temperature dependent behaviour of the properties.

\subsection{Cracking criteria of RCC gravity dam under triaxial stress states}

In order to check the safety of the dam against cracking under Triaxial Stress States a new mathematical model has been developed during the present study to predict the crack development in RCC dam during the construction and operation stages. The respective failure criteria for mass concrete in principal stress space and octahedron stress space which proposed by (Wang, Song 2008) is adopted in the developed model.

The cracking criterion suggested by Wang and Song (2008) is a function of octahedral shear stress $\tau_{\text {oct }}$ and octahedral normal stress $\sigma_{o c t}$

$$
\begin{gathered}
\sigma_{o c t}=\frac{\left(\sigma_{1}+\sigma_{2}+\sigma_{3}\right)}{3} \\
\tau_{o c t}=\frac{1}{3}\left[\left(\sigma_{1}-\sigma_{2}\right)^{2}+\left(\sigma_{2}-\sigma_{3}\right)^{2}+\left(\sigma_{3}-\sigma_{1}\right)^{2}\right]^{1 / 2} .
\end{gathered}
$$

Let $\sigma_{1}, \sigma_{2}$ and $\sigma_{3}$ denote the tensile stress, intermediate stress and compressive stress at failure under triaxial C-C-T, respectively. The values of $\frac{\sigma_{o c t}}{f_{c}}$ and $\frac{\tau_{o c t}}{f_{\mathcal{C}}}$ will be regressed in a parabolic formula as follows (Wang, Song 2008):

$$
\frac{\tau_{o c t}}{f_{c}}=0.0655-0.9097 \frac{\sigma_{o c t}}{f_{c}}-0.08936\left(\frac{\sigma_{o c t}}{f_{c}}\right)^{2} .
$$

This formula to be compatible with RCC construction sequence further modified as: 


$$
\begin{aligned}
& \tau_{o c t}(t)^{u l t}= \\
& {\left[0.0655-0.9097 \frac{\sigma_{o c t}(t)}{f_{c}(t)}-0.08936\left(\frac{\sigma_{o c t}(t)}{f_{c}(t)}\right)^{2}\right] f_{c}(t) .}
\end{aligned}
$$

In triaxial tension $\sigma_{1}<\sigma_{2}<\sigma_{3}<0.00$ the triaxial tensile strength is equal to uniaxial tensile strength $f_{t}(t)$. In tension-compression - compression (T-C-C), $\sigma_{1}>0.00$, and $\sigma_{2}<\sigma_{3}<0.00$, the maximum strength is given by Eqn (22).

The variation in the compressive strength with time is calculated according to (ACI 1995), which relates the elastic modulus to the compressive strength as:

$$
E(t)=4750 \sqrt{f_{c}(t)},
$$

where $E(t)$ is the elastic modulus, which is time and temperature dependent Eqn (10). The tensile strength of RCC material is evaluated using the model that developed by (Zdiri et al. 2008):

$$
f_{t}=0.214 f_{c}^{0.69} .
$$

Taking into account this criterion, cracking on an element begins where the relation $\psi_{c r}$ drop below the allowable value. The following expression is defining the crack index (Abdulrazeg et al. 2010b):

$$
\psi_{c r}=\frac{\tau_{o c t}(t)^{u l t}}{\tau_{o c t}(t)},
$$

it can be verified that when $\psi_{c r}>1.0$ the element is not cracked, and cracking occurs when $\psi_{c r}<1.0$.

Finally, the allowable octahedral shear stress will be determined using Eqn (22) and based on that the crack safety factor is generated by Eqn (25). If safety coefficient of crack is greater than one, the element will be considered safe against crack. But if the coefficient is less than one, crack will develop in the dam body.

\subsection{Gradient cracking criteria}

Design specification for concrete arch dam (Abdulrazeg 2012) demands that the tensile stress should be controlled by the following equation:

$$
\begin{gathered}
\varepsilon_{T} \leq \frac{\varepsilon_{p}}{K_{f}} ; \\
\varepsilon_{T}=\Delta T \times \alpha,
\end{gathered}
$$

where: $\varepsilon_{T}$ is tensile strain of concrete which caused by temperature difference $\Delta T ; \alpha$ is thermal expansion coefficient; $\varepsilon_{p}$ is ultimate tensile strain of concrete; and $K_{f}$ is safety coefficient and range from 1.3-1.8 (SL2822003). The laboratory test reported by Dunstan (1981) showed that a typical value of the tensile strain capacity is $80 \mu \mathrm{mm}$.

\section{Development of finite element code}

In previous discussion, the formulation in Sections 2 (temperature), Sections 6 (creep) and Sections 7 (crack analysis) are implemented in the present research program (Abdulrazeg 2012). Based on that, a threedimensional finite element program was developed and the following are the features of the finite element code.

1) Simulation of sequence of construction for both gravity and arch RCC dam;

2) Thermal analysis;

3) Structural analysis with or without creep effect;

4) Combined thermal and structural analysis with or without creep effect;

5) Crack safety evaluation.

The desired outcome of the modified code with respect to both two and three-dimensional finite element method are:

-Spatial distribution of temperature and its evolution with time;

- The stress distribution during and following the dam construction;

-Assessment of the crack occurrence either at short or long term.

The developed finite element program is written in FORTRAN language and can work under power station environment. The flowchart shown in Figure 1 represents the architecture of the program. The main program calls 36 main subroutines, each main subroutine calls another sub-subroutines and the code is about 7198 lines (Abdulrazeg 2012):

1) Divided the structure into stages according to construction schedule;

2) Divided each stage into several times;

3) Perform the thermal analysis, if only the temperature field analysis is desired, then the program moves to the next time step;

4) Perform stress analysis, and in case the creep is taken into consideration, the computational procedures in Section 6 will be preformed;

5) Performing crack prediction using the procedures in Section 7.

\section{Analysis of actual RCC arch dam}

The Karun III has been taken as a case study for the purpose of verification of the developed code. The Karun III dam is a hydroelectric dam on the Karun River in the province of Khuzestan, Iran. The dam is unsymmetrical double curvature type, $205 \mathrm{~m}$ high from the foundation. Its foundation width is $29.5 \mathrm{~m}$. The arch dam design is an ideal one for a dam built in a narrow, rocky gorge to hold back water in a reservoir. Table 1 shows the main characteristics of the dam. Figure 2 shows original view and plan view of Karun III arch dam. The construction of the dam was started on 1995 and was put in operation 2005 (Karun III technical report 1995). The dam was originally designed as conventional concrete arch dam. In this study, RCC technology has been ascertained as an alternative method to reduce the cost of the project. 


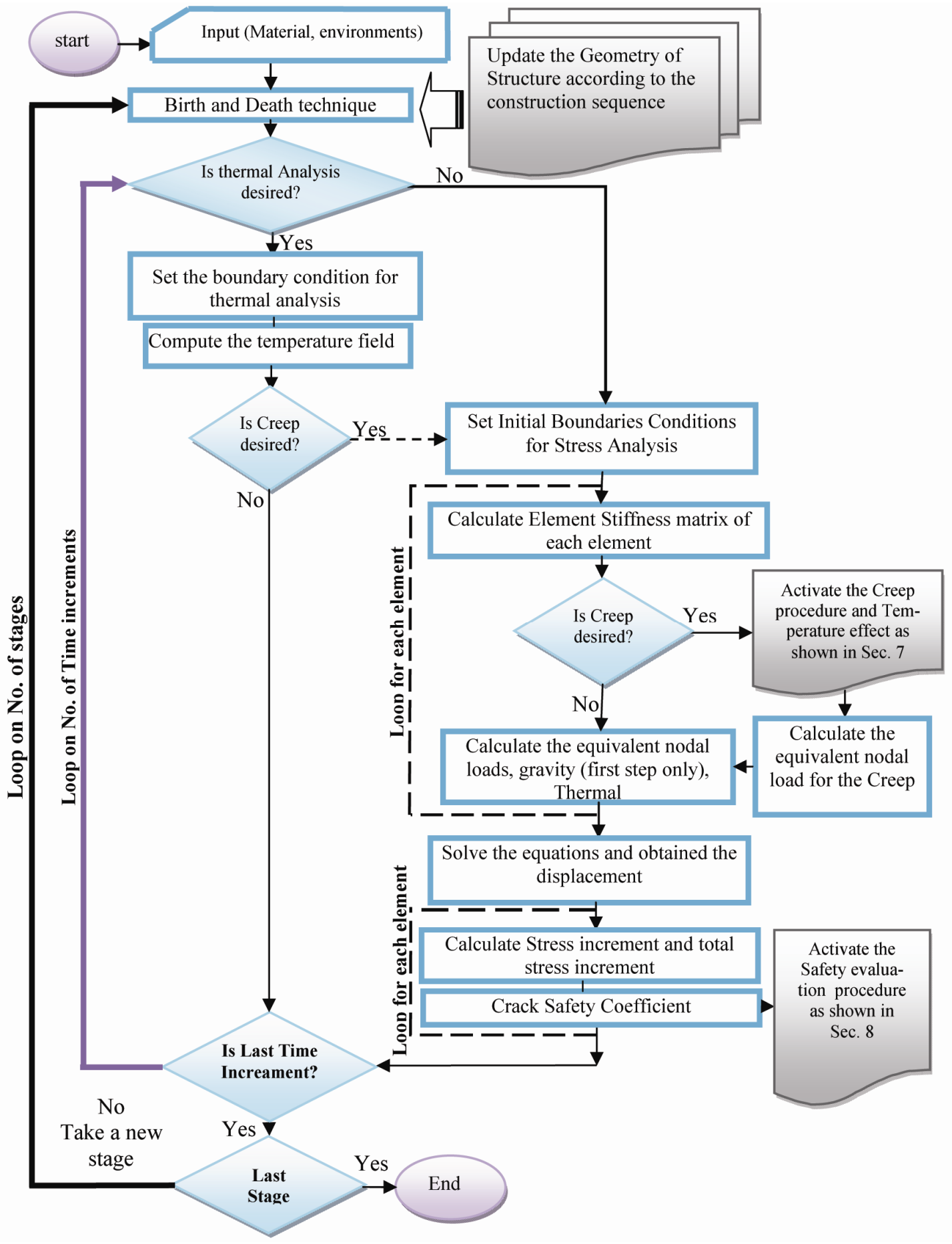

Fig. 1. Program flow chart of the computer code (with temperature and creep modification)

Table 1. Main characteristics of Karun III concrete arch dam

\begin{tabular}{lc}
\hline \multicolumn{1}{c}{ Characteristic } & Quantity \\
\hline Maximum height above foundation & $205.0 \mathrm{~m}$ \\
Crest width & $5.5 \mathrm{~m}$ \\
Base width & $29.5 \mathrm{~m}$ \\
Crest length & $462.0 \mathrm{~m}$ \\
Placed concrete & $1300000.0 \mathrm{~m}^{3}$ \\
Reservoir normal capacity & $2,970,000,000 \mathrm{~m}^{3}$ \\
\end{tabular}

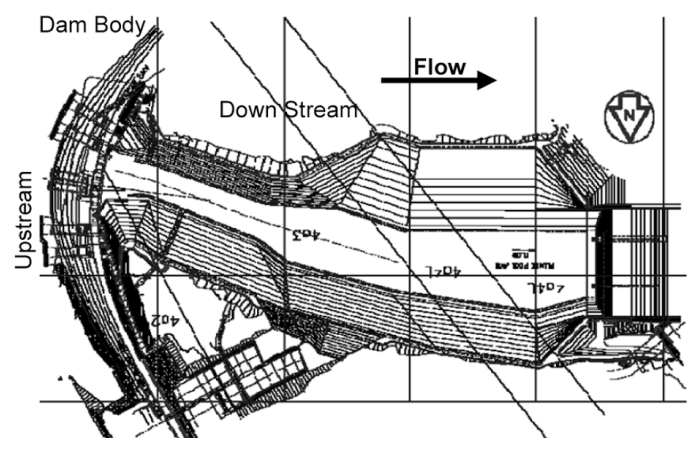

Fig. 2. Plan view of Karun III dam 
The dam site is generally hot and occasionally humid. Summertime temperatures routinely exceed $50^{\circ} \mathrm{C}$. Khuzestan province is known as one of the hottest state in the world.

\subsection{Material properties and site conditions}

The material properties for the RCC and the rock foundation are tabulated in Table 2. These values were chosen based on values reported in the literature for RCC materials which are used in arch RCC dam (Xie, Chen 2005). The creep experimental data which were reported in the literature by (Zhang 1995) for RCC material have been adopted in the present study; these data are tabulated in the Table 3. In addition, the average monthly air temperatures at the project site are plotted in Figure 3 according to NASA organization (www.Eosweb.larc.nasa.gov/sse/ RETScreen). The average annual wind speed which is $4.0 \mathrm{~m} / \mathrm{s}$ recorded at the site.

Table 2. Thermal and mechanical properties for Karun III concrete arch dam

\begin{tabular}{lcc}
\hline Characteristic & RCC & Rock \\
\hline Cement $\left(\mathrm{Kg} / \mathrm{m}^{3}\right)$ & 90 & \\
Fly ash $\left(\mathrm{Kg} / \mathrm{m}^{3}\right)$ & 110 & \\
Coefficient of thermal expansion & $3.04 \mathrm{E}-6$ & $4.2 \mathrm{E}-6$ \\
Thermal conductivity $\left(\mathrm{KJ} / \mathrm{m} \mathrm{h}^{\circ} \mathrm{C}\right)$ & 8.314 & 10.0 \\
Specific heat $(\mathrm{J} /(\mathrm{kg} . \mathrm{K}))$ & 1080 & 1500 \\
Elastic Modulus $(\mathrm{MPa})$ & 18200 & 24000 \\
\hline
\end{tabular}

Table 4. Construction schedule of Karun III RCC Arch Dam

\begin{tabular}{|c|c|c|c|c|c|}
\hline $\begin{array}{c}\text { Time of pouring } \\
\text { (D-M-Y) }\end{array}$ & $\begin{array}{l}\text { Height of casting } \\
\text { (m) }\end{array}$ & Time of pouring & $\begin{array}{l}\text { Height of casting } \\
(\mathrm{m})\end{array}$ & Time of pouring & $\begin{array}{l}\text { Height of casting } \\
\text { (m) }\end{array}$ \\
\hline $3 / 1 / 1995$ & 1.2 & $3 / 29 / 1997$ & 72.0 & $5 / 11 / 1999$ & 144.0 \\
\hline $3 / 30 / 1995$ & 3.0 & $4 / 23 / 1997$ & 75.0 & $5 / 29 / 1999$ & 147.0 \\
\hline $4 / 20 / 1995$ & 6.0 & $9 / 16 / 1997$ & 78.0 & 6/20/1999 & 150.0 \\
\hline $5 / 14 / 1995$ & 9.0 & $10 / 10 / 1997$ & 81.0 & 7/10/1999 & 153.0 \\
\hline $9 / 7 / 1995$ & 12.0 & $11 / 3 / 1997$ & 84.0 & $10 / 1 / 1999$ & 156.0 \\
\hline $10 / 1 / 1995$ & 15.0 & $12 / 27 / 1997$ & 87.0 & $10 / 20 / 1999$ & 159.0 \\
\hline $10 / 25 / 1995$ & 18.0 & $1 / 20 / 1998$ & 90.0 & 11/10/1999 & 162.0 \\
\hline $11 / 18 / 1995$ & 21.0 & $2 / 16 / 1998$ & 93.0 & 11/29/1999 & 165.0 \\
\hline $12 / 11 / 1995$ & 24.0 & $3 / 9 / 1998$ & 96.0 & $12 / 20 / 1999$ & 168.0 \\
\hline $1 / 5 / 1996$ & 27.0 & $4 / 3 / 1998$ & 99.0 & $1 / 11 / 2000$ & 171.0 \\
\hline $1 / 29 / 1996$ & 30.0 & $5 / 27 / 1998$ & 102.0 & $1 / 29 / 2000$ & 174.0 \\
\hline $2 / 22 / 1996$ & 33.0 & $6 / 10 / 1998$ & 105.0 & $2 / 21 / 2000$ & 177.0 \\
\hline $3 / 16 / 1996$ & 36.0 & 7/1/1998 & 108.0 & $3 / 11 / 2000$ & 180.0 \\
\hline $4 / 2 / 1996$ & 39.0 & $10 / 1 / 1998$ & 111.0 & $3 / 30 / 2000$ & 183.0 \\
\hline $4 / 21 / 1996$ & 42.0 & $10 / 21 / 1998$ & 114.0 & $4 / 19 / 2000$ & 186.0 \\
\hline $5 / 26 / 1996$ & 45.0 & $11 / 10 / 1998$ & 117.0 & $5 / 11 / 2000$ & 189.0 \\
\hline $9 / 21 / 1996$ & 48.0 & 11/30/1998 & 120.0 & $5 / 30 / 2000$ & 192.0 \\
\hline $10 / 14 / 1996$ & 51.0 & $12 / 20 / 1998$ & 123.0 & $6 / 19 / 2000$ & 195.0 \\
\hline $11 / 8 / 1996$ & 54.0 & $1 / 10 / 1999$ & 126.0 & $7 / 10 / 2000$ & 198.0 \\
\hline $12 / 1 / 1996$ & 57.0 & $1 / 30 / 1999$ & 129.0 & $10 / 1 / 2000$ & 201.0 \\
\hline $12 / 25 / 1996$ & 60.0 & 2/20/1999 & 132.0 & $10 / 21 / 2000$ & 205.0 \\
\hline $1 / 19 / 1997$ & 63.0 & $3 / 10 / 1999$ & 135.0 & & \\
\hline $2 / 12 / 1997$ & 66.0 & $3 / 30 / 1999$ & 138.0 & & \\
\hline $3 / 5 / 1997$ & 69.0 & $4 / 21 / 1999$ & 141.0 & & \\
\hline
\end{tabular}

Table 3. Creep data for RCC and CMC materials (Zhang 1995)

\begin{tabular}{r|r|r|r|r|c}
\hline Material & \multicolumn{2}{|c|}{$\alpha_{i}$} & \multicolumn{1}{c|}{$\beta_{i}$} & \multicolumn{1}{c|}{$\delta_{i}$} & $\mathrm{D}$ \\
\hline \multirow{3}{*}{ CVC } & 1 & 0.35494 & 0.4836 & 0.35361 & $\ldots \ldots \ldots$ \\
& 2 & 3.7335 & -0.186 & 0.01248 & $\ldots \ldots$. \\
& 3 & -2.5644 & 0.1378 & 0.03264 & 0.835 \\
\hline \multirow{3}{*}{ RCC } & 1 & 0.05886 & 0.38362 & 1.356 & $\ldots \ldots$ \\
& 2 & 7.4729 & -11.115 & 0.08919 & $\ldots \ldots$ \\
& 3 & -5.2079 & 7.9619 & 0.078675 & 4.2808 \\
\hline
\end{tabular}

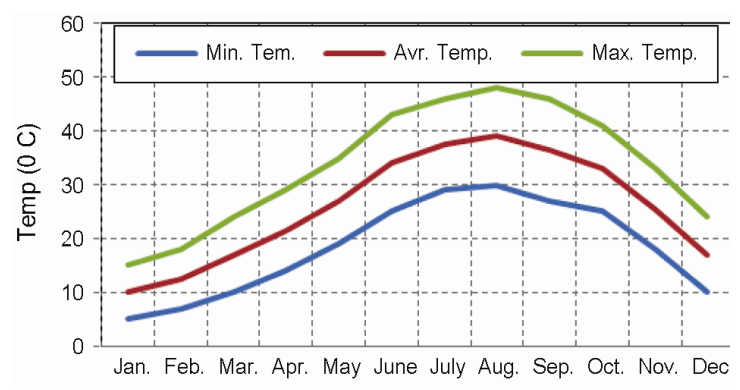

Fig. 3. Monthly air temperature at project site

\subsection{Construction schedule}

In this study, the construction schedule of $205.0 \mathrm{~m}$ height RCC arch dam is proposed. The construction of the dam is planned according to a similar project was reported in the literature (Xie, Chen 2005), to be realistic, the construction schedule is adjusted based on the corresponding geometry of the adopted project. However, during the high temperature of the summer time, the construction will be stopped during July, August and September. Table 4 shows the proposed construction schedule of the dam. 


\subsection{Finite element modeling of RCC arch dam}

The three-dimensional finite element model of the block foundation and dam body is shown in Figure 4. The finite element of the dam body is generated according to the construction Schedule which was given in Table 4. Twenty node isoparametric element is used for propose of discretization of the dam body and foundation block. 2880 isoparametric elements are used to model the foundation block and 560 elements to model the dam body, over all 17627 nodes have been used to define the coordinate of the finite element mesh of the entire system.

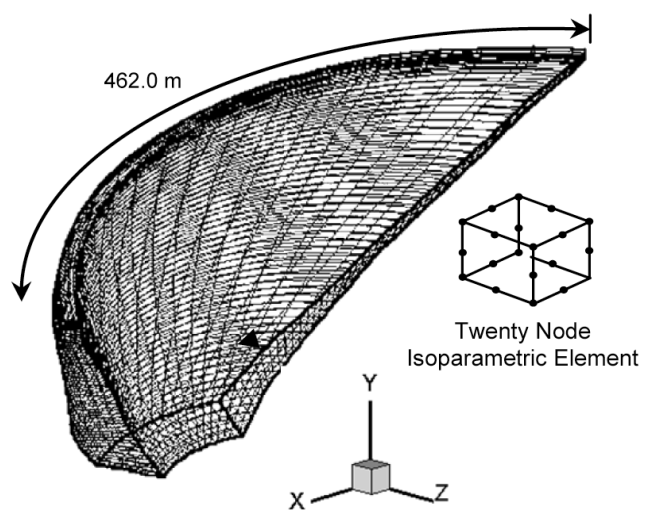

(a) 3D View of finite element mesh for dam body

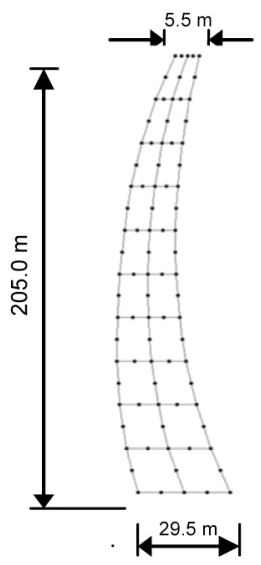

(b) Cross section of central block

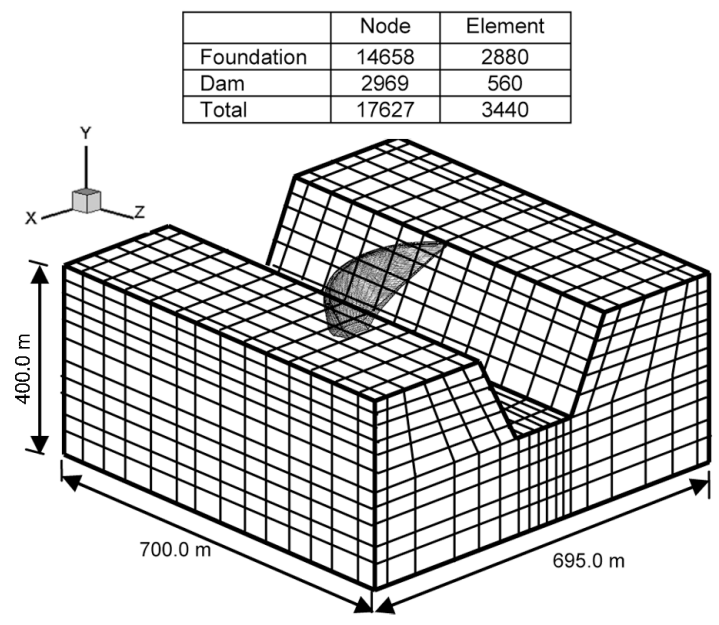

(c) 3D View of finite element mesh for block foundation

Fig. 4. Finite element modeling of Karun III RCC arch dam

\subsection{Simulation of the initial conditions}

The temperature distribution in the rock foundation and the RCC placing temperature are the two initial conditions considered in the analysis. In this case of study, the main annual temperature recorded near the project site is $25.6^{\circ} \mathrm{C}$ it was assigned first to the all nodes of the block foundation as an initial condition. Then heat transfer between the atmospheric temperature and the block foundation was performed for a period of two years using the average monthly temperature (Ishakawa 1991). The RCC placing temperature is taken as the environmental temperature at the casting time but not permitted to exceed $30{ }^{\circ} \mathrm{C}$.

\section{Results and discussion}

\subsection{Temperature distribution of Karun III RCC arch dam}

According to the proposed schedule which given in Table 4, the thermal analysis is performed. The construction was started on March 1995 and completed in October 2000. However, the construction process was stopped every year for three months to avoid the work in very hot weather at the construction site during the summer period (July, August and September).

Temperature distribution in the body of the arch dam at the end of construction for the crown cantilever of the central section and different levels of the dam $(20 \mathrm{~m}$, $75 \mathrm{~m}$, and $95 \mathrm{~m}$ ) are shown in Figures 5 and 6 respectively. Higher temperatures zones are observed at the lower elevation levels near the abutments as shown in Figure 6. This can be anticipated to the higher thickness at these locations which provide high insulating property compared to the upper levels where the dam thickness decreased progressively.

In addition, high temperature concentration was observed at the upper elevation levels $(150 \mathrm{~m}$ and $195 \mathrm{~m})$ of the dam that because, the hydration process is still high in this part. However, the temperature at the lower part of the dam is $42{ }^{\circ} \mathrm{C}$ and it reduced to the air temperature at the boundary condition.

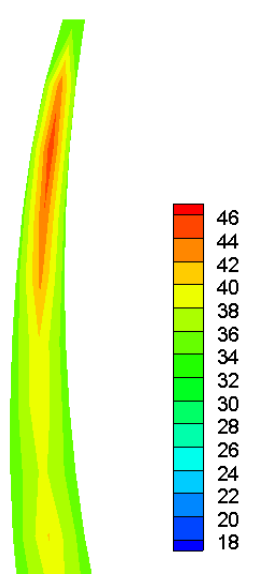

Fig. 5. Temperatures distribution for the crown cantilever of the central block 

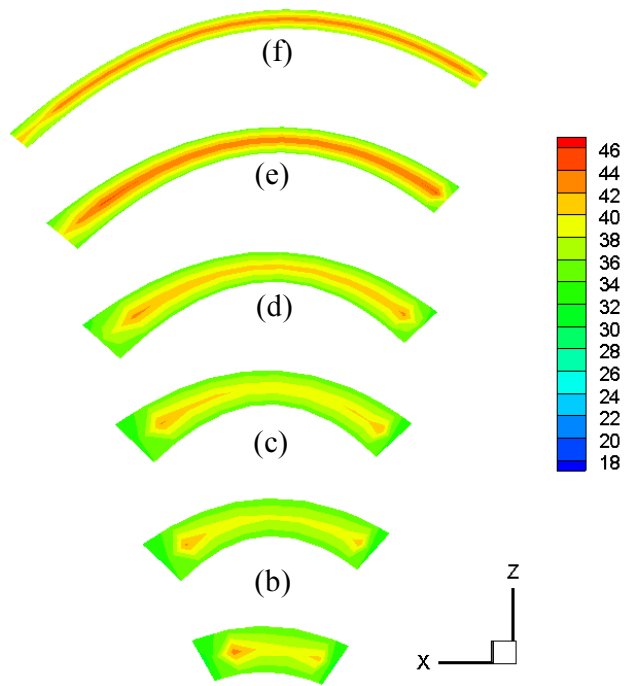

(a)

(a) $20.0 \mathrm{~m}$ from the base; (b) $75.0 \mathrm{~m}$ from the base; (c) $95.0 \mathrm{~m}$ from the base; (d) $105.0 \mathrm{~m}$ from the base; (e) $150.0 \mathrm{~m}$ from the base; (f) $195.0 \mathrm{~m}$ from the base

Fig. 6. Temperatures distribution at different levels of the dam at the end of construction

\subsubsection{Gradient cracking control standard}

According to the methodology described in Section 7.2, allowable gradient strain is determined and compared with a computed strain based on the predicted temperature obtained from finite element analysis. The maximum internal temperature is $42.0{ }^{\circ} \mathrm{C}$ (determined from the plots). The minimum temperature is $12.0^{\circ} \mathrm{C}$ (based on the annual temperature cycle) taken from Figure 3 . The coefficient of thermal expansion is given in Table 2. The calculated induced strain based on Eqn (27) is $166.8 \mu \mathrm{mm}$, which exceeded the allowable strain (Eqn (26)). This could be controlled by determining the proper spacing of the RCC blocks.

\subsection{Stress analysis of Karun III RCC arch dam}

A viscoelastic mathematical model which involves ageing and temperature effects (presented in Section 6) is adopted for the stress analysis. First, the thermal analysis is performed for each time step. Then the degree of equivalent hydration period is determined. Based on this degree the mechanical properties such as elastic modulus (Eqn (12)) and creep compliance (Eqn (11)) are calculated. Finally, the crack safety factor will be determined for each time step (Fig. 1).

Figure 7 shows the principal stress contours $\sigma_{1}(\mathrm{MPa})$ in the dam body, the result indicates that, the tensile stresses developed mainly at the dam bottom and the abutment boundaries, because of the contact between two dissimilar materials. In addition, the tensile stress has been observed at the upstream side (1.6 MPa) due to arch action combined with the restraint against environmental thermal variation, which doesn't exceed the limit according to U. S. crops of engineering (ACI. EM 1110-2, 2006).
On the other hand, compressive stress contours are developed at the downstream side due to the arch action and gradually decreased in the direction of boundaries.

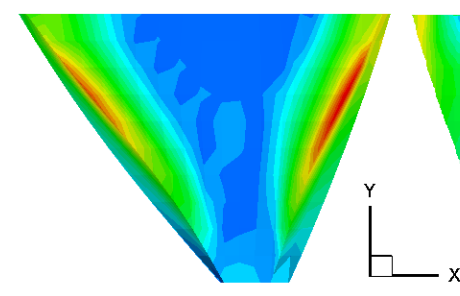

(b)

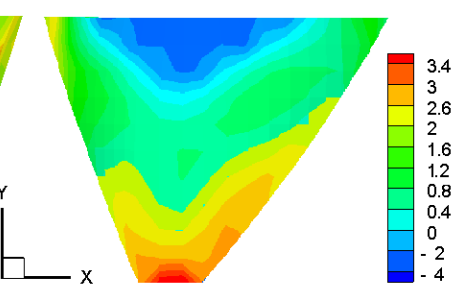

(a)

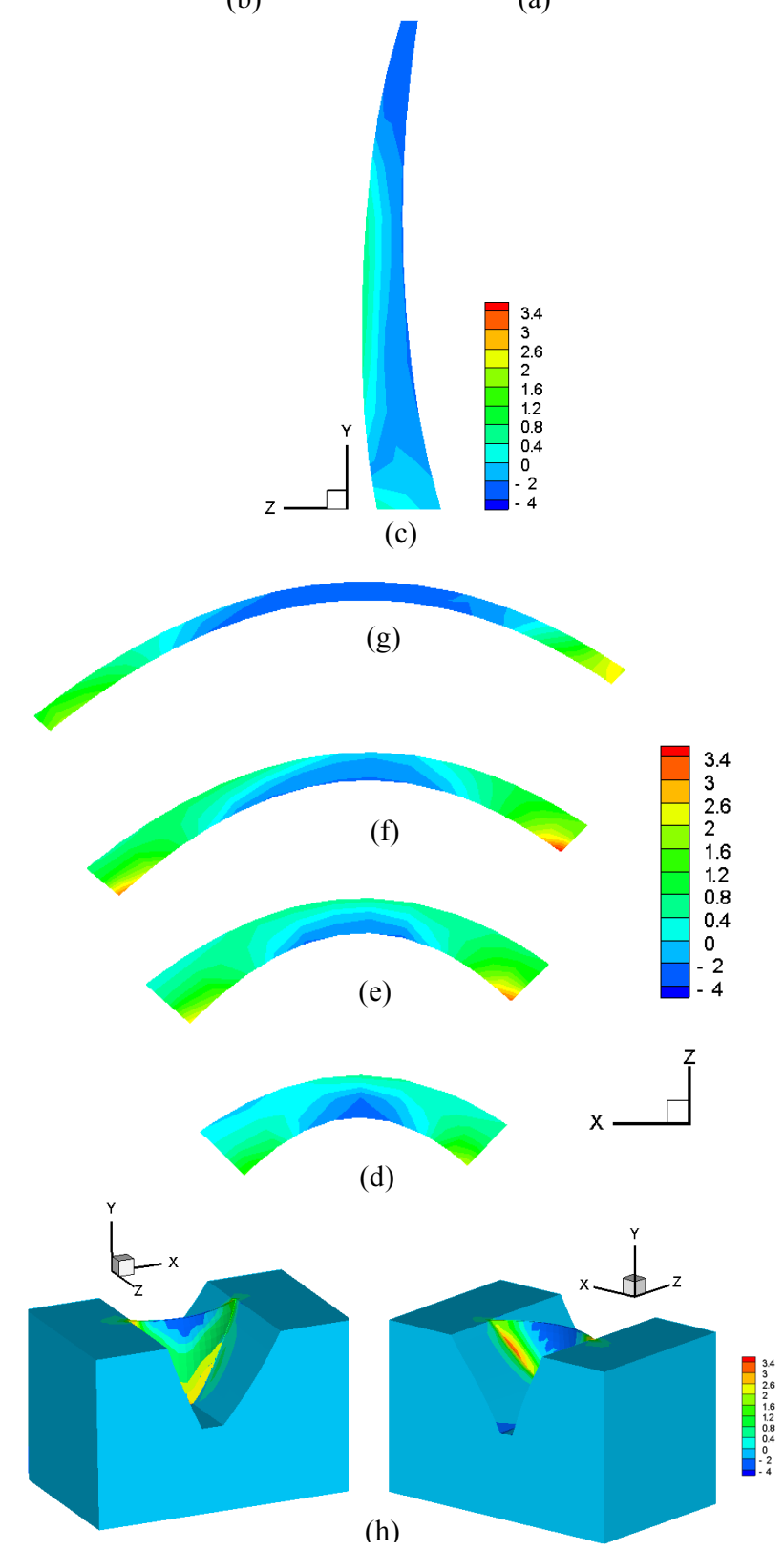

(a) upstream face; (b) downstream face; (c) crown cantilever section; (d) horizontal section at level $=75 \mathrm{~m}$; (e) horizontal section at level $=95 \mathrm{~m}$; (f) horizontal section at level $=105 \mathrm{~m}$; (g) horizontal section at level $=150 \mathrm{~m}$; (h) block foundation and the dam body

Fig. 7. Principal stress distribution $\left(\sigma_{1}\right)$ at the end of dam construction 
Figure 8 shows contour plots for the evolution of the intermediate principal stress $\sigma_{2}(\mathrm{MPa})$. It can notice that, tensile stresses developed at the same locations of the principal stress $\sigma_{1}$ with smaller values. In addition, high compressive stresses zones are observed at some level at the downstream side (75.0 and $150.0 \mathrm{~m}$ ).

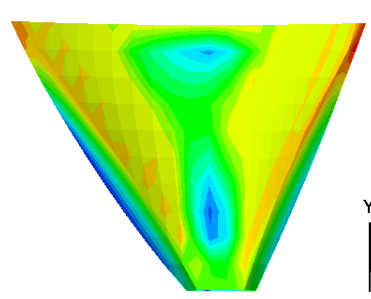

(b)
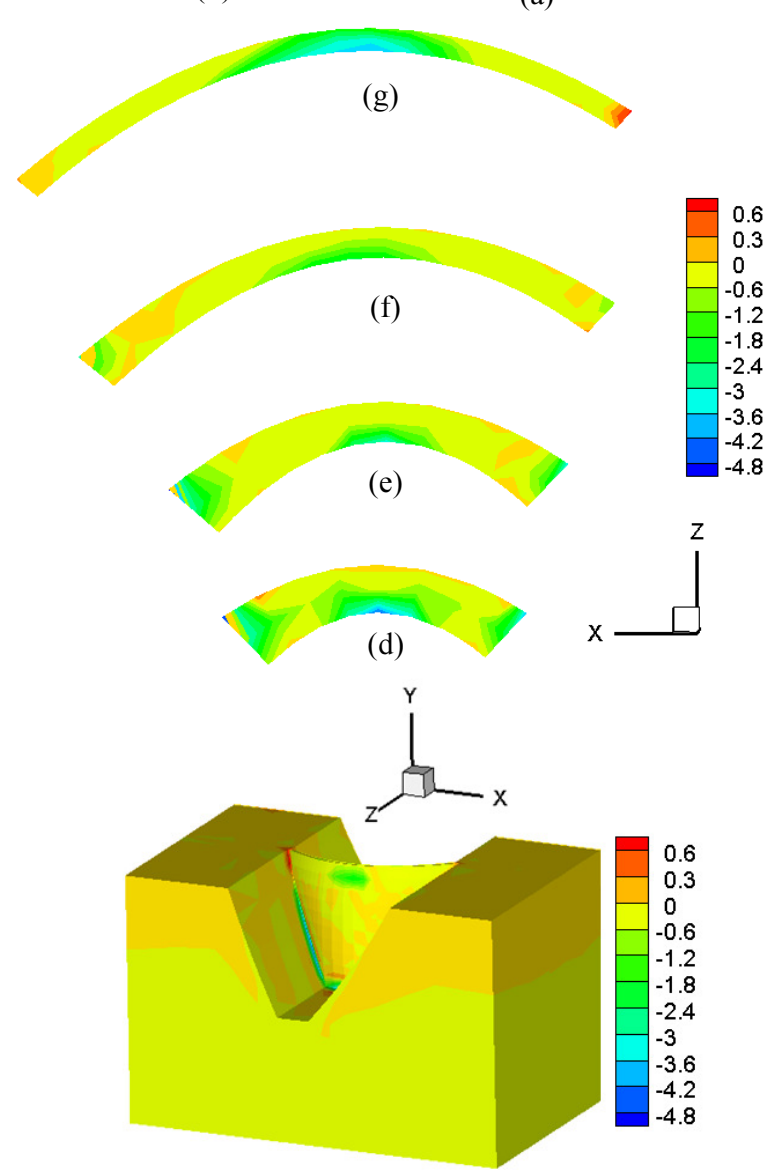

(h)

(a) upstream face; (b) downstream face; (c) crown cantilever section; (d) horizontal section at level $=75 \mathrm{~m}$; (e) horizontal section at level $=95 \mathrm{~m}$; (f) horizontal section at level $=105 \mathrm{~m}$; (g) horizontal section at level $=150 \mathrm{~m}$; (h) block foundation and the dam body

Fig. 8. Principal stress distribution $\left(\sigma_{2}\right)$ at the end of dam construction

Figure 9 shows the distribution of the minimum principal stress $\sigma_{3}$. High compressive stress zones concentrated at the upper part of the upstream dam side which gradually decreased in the direction of abutment sides. Generally, the compressive stresses developed in the dam body during the construction are not exceeding the allowable compressive strength specified by ACI 207 (1999).

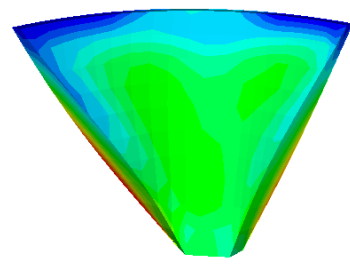

(b)

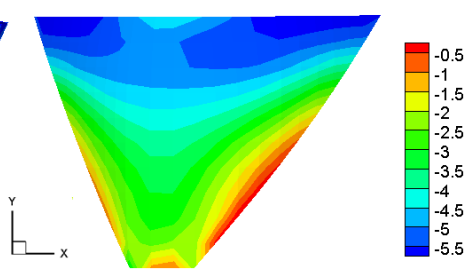

(a)

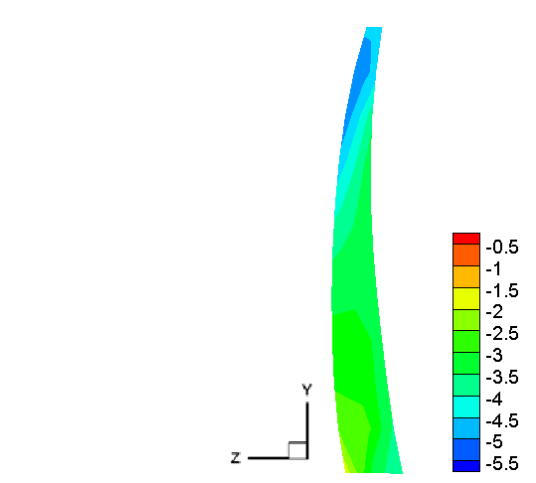

(c)
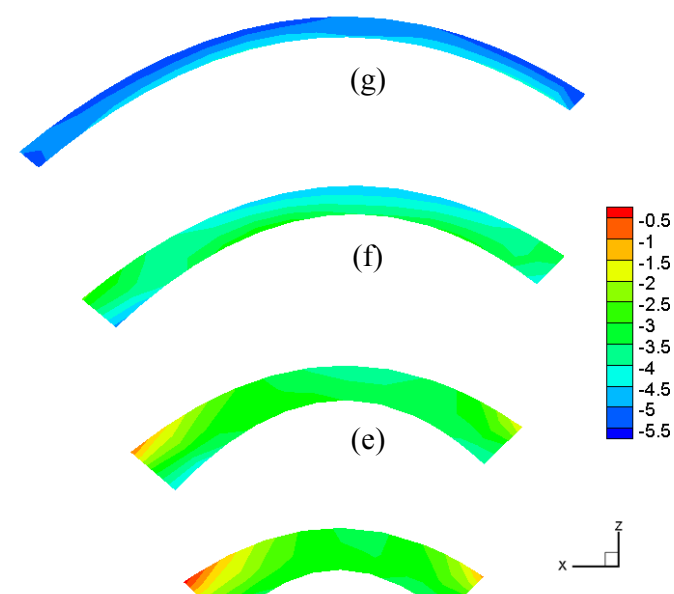

(d)

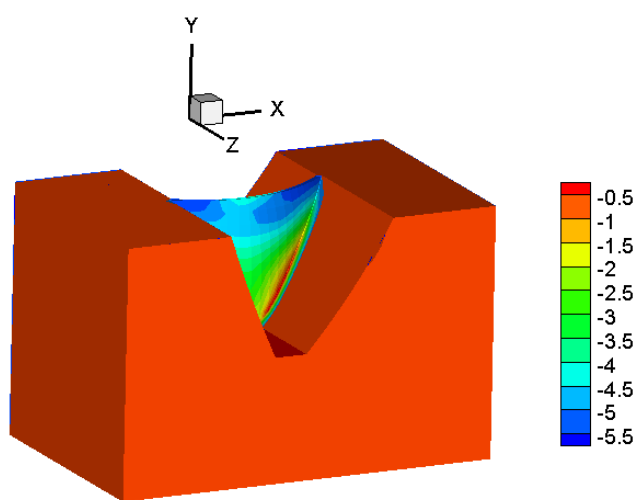

(h)

(a) upstream face; (b) downstream face; (c) crown cantilever section; (d) horizontal section at level $=75 \mathrm{~m}$; (e) horizontal section at level $=95 \mathrm{~m}$; (f) horizontal section at level $=105 \mathrm{~m}$; (g) horizontal section at level $=150 \mathrm{~m}$; (h) block foundation and the dam body

Fig. 9. principal stress distribution $\left(\sigma_{3}\right)$ at the end of dam construction 


\subsection{Crack analysis and safety evaluation}

Simultaneously during the stress analysis the crack safety factor will be calculated using the procedure described in Section 7.1 at each Gaussian point. The safety factor against cracking in any point of a generic finite element is determined using Eqn (25).

An attempt is made to draw the crack safety factor at level of $105.0 \mathrm{~m}$ along the dam width for different construction levels as shown in Figure 10. Observing Figure 10, it is verified that the crack safety factor along the section for different construction height at that particular lift is greater than the allowable limit. Thus, it is considered to be safe against the crack development. However, near the abutments of the dam, the crack safety factor is dropped below the limit which coincides with higher tensile stress zone (Fig. 7f). Hence, special attention must be given to locations during the design of the dam.
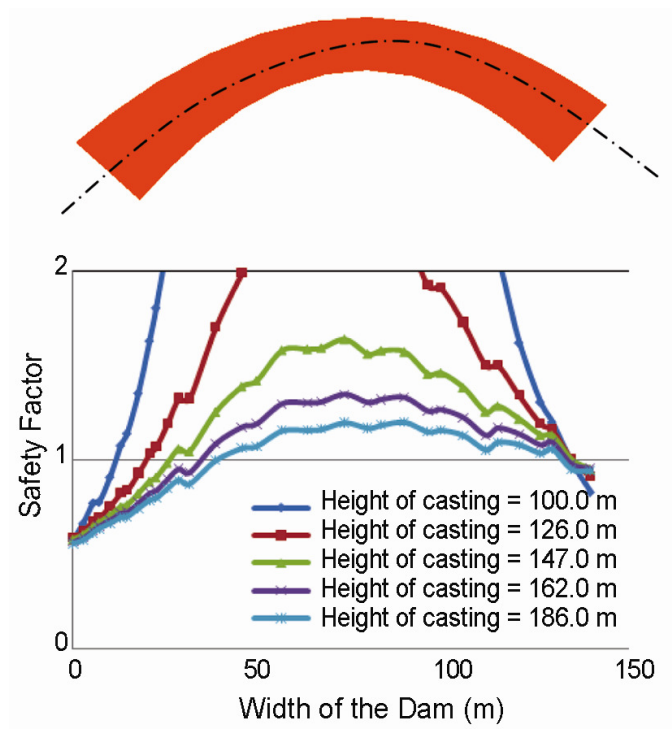

Fig. 10. Safety factors path along the dam width (EL.105.0 m)

\section{Conclusion and remarks}

The capability of the developed system for thermal and structural analysis of RCC arch dam has been demonstrated through analyzing 205.0 height Karun III arch dam located in Iran. In this study, RCC technology has been as ascertained as an alternative method. The analysis was carried out during the construction stages only.

Based on the limitations and assumptions used in the present study, the following points can be drawn:

- The finite element code developed in this study is capable of simulating the structural response of arch $R C C$ dams efficiently. This is clearly shown from the reasonable stresses distributions obtained;

- Higher temperature zones are formed at the center part of the dam, especially at the thicker places near the abutments which gradually decreased in values to reach the air temperature at the boundaries. The requirements of strength and crack resistance are greater in high Zone, because of the adiabatic temperature is high in this zone;
- High Tensile stresses have been observed at the dam bottom and the abutment boundaries in the upstream side section due to the restriction from the abutment and foundation rock. This is because of low temperature, ranging from dam foundation to abutment and there is no transverse joint in RCC arch dam. Engineers should pay special attention to this zone. Moreover, the tensile stress has been observed at the upstream side due to arch action combined with the restraint against environmental thermal variation;

- High compressive stress zones concentrated at the upper part of the upstream dam side which gradually decreased in the direction of abutment sides.

\section{References}

Abdulrazeg, A. A.; Noorzaei, J.; Khanehzaei, P.; Jaafar, M. S.; Mohammed, T. A. 2010. Effect of temperature and creep on roller compacted concrete dam during the construction stages, CMES: Computer Modeling in Engineering \& Sciences 68(3): 239-268.

Abdulrazeg, A. A. 2012. Modeling of Combined Thermal and Mechanical Actions in Roller Compacted Concrete Dam By Finite Element Method: PhD Thesis. Civil Engineering Department, Universiti Putra Malaysia Malaysiy.

Abdulrazeg, A. A.; Noorzaei, J.; Khanehzaei, P.; Jaafar, M. S.; Mohammed, T. A., Thanoon, W. A. 2011. Cracking safety evaluation of massive concrete structures, Journal of Key Engineering Materials 462-463: 1403-1408.

http://dx.doi.org/10.4028/www.scientific.net/KEM.462463.1403

ACI318. 1995. Building code requirements for structural concrete. USA: ACI $318 \mathrm{M}-95$.

Agullo, L.; Aguado, A. 1995. Thermal behavior of concrete dams due to environmental actions, Journal of Dam Eng. VI: 3-21.

American Concrete Institute. 1999. Roller-Compacted Mass Concrete, ACI 207.5R-99, Farmington Hills.

Araújo, J. M.; Awruch, A. M. 1998. Cracking safety evaluation on gravity concrete dams during the construction phase, Computers \& Structures 66(1): 93-104.

http://dx.doi.org/10.1016/S0045-7949(97)00048-5

Atrushi, D. S. 2003. Tensile and compressive creep of early age concrete: testing and modelling: $\mathrm{PhD}$. The Norwegian University of Science and Technology.

Bayagoob, K. H.; Noorzaei, J.; Abdularzeg, A. A.; Al-Karni, A. A.; Jaafar, M. S. 2010. Coupled thermal and structural analyses of roller compacted concrete dams by threedimensional finite element method, J. Structural Engineering and Mechanics 36.

Bayagoob, K. H.; Noorzaei, J.; Jaafar, M. S.; Thanoon, W. A.; Abdularzeg, A. A. 2010. Modelling heat exchange between RCC dam and reservoir, J. Engineering and Computational Mechanics, Ice 163.

Bazant, Z. P.; Cusatis, G.; Cedolin, L. 2004. Temperature effect on concrete creep modeled by microprestresssolidification theory, Journal of Engineering MechanicsProceedings of the ASCE 130(Special issue: Constitutive modeling of geomaterials): 691-699. http://dx.doi.org/10. 1061/(ASCE)0733-9399(2004)130:6(691)

Bosnjak, D. 2000. Self-induced cracking problems in hardening concrete structures: PhD. Norwegian University of Science and Technology, ISBN 82-7984-151-2.

Cervera, M.; Oliver, J.; Prato, T. 2000. Simulation of construction of RCC dams. I: temperature and aging, Journal of Structural Engineering 126(9): 1062-1069. http://dx.doi.org/10.1061/(ASCE)07339445(2000)126:9(1062) 
Conrad, M.; Aufleger, M.; Malkawi, A. 2003. Investigations on the modulus of elasticity of young RCC, in Berga, L. (Ed.). Proceedings of the Fourth International Symposium on Roller Compacted Concrete (RCC) Dams, Madrid, Spain, 729-733.

Crichton, A.; Benzenati, I.; Qiu, T.; Williams, J. 1999. Kinta RCC dam-are over-simplified thermal structural analyses valid, ANCOLD Issue. $10 \mathrm{p}$.

Du, C.; Liu, G. 1994. Numerical procedure for thermal creep stress in mass concrete structures, Communications in Numerical Methods in Engineering 10(7): 545-554. http://dx.doi.org/10.1002/cnm.1640100706

Dunstan, M. R. H. 1981. Rolled concrete for dam - laboratory trial of high fly ash content concrete, CIRIA Technical Note 105, London.

Hedlund, H. 1996. Stresses in high performance concrete due to temperature and moisture variations at early ages: Licentiate Thesis. Luleå University of Technology.

Ishikawa, M. 1991. Thermal stress analysis of a concrete dam, Computers \& Structures 40(2): 347-352. http://dx.doi.org/10.1016/0045-7949(91)90360-X

Jonasson, J. E. 1994. Modelling of temperature, moisture and stresses in young concrete: PhD Doctoral Thesis. Luleå University of Technology.

Luna, R.; Wu, Y. 2000. Simulation of temperature and stress fields during RCC dam construction, Journal of Construction Engineering and Management 126(5): 381388. http://dx.doi.org/10.1061/(ASCE)0733-9364(2000) $126: 5(381)$

Malkawi, A. I. H.; Mutasher, S. A.; Qiu, T. J. 2003. Thermalstructural modeling and temperature control of roller compacted concrete gravity dam, Journal of performance of constructed facilities 17(4): 177-187. http://dx.doi.org/ 10.1061/(ASCE)0887-3828(2003)17:4(177)

Neville, A. M.; Dilger, W. H.; Brooks, J. J. 1983. Creep of plain and structural concrete. New York Construction Press London. $361 \mathrm{p}$.

Noorzaei, J.; Bayagoob, K. H.; Thanoon, W. A.; Jaafar, M. S. 2006. Thermal and stress analysis of Kinta RCC dam, Engineering Structures 28(13): 1795-1802. http://dx.doi.org/10.1016/j.engstruct.2006.03.027

Nilipour, N. 2003. Study of arch concrete dams constructed by $R C C$ method, Switzerland (in Press).

Penghui, L.; Hong, C. 2007. 3-D Simulating analysis for thermal control during constructionperiod on Dahuashui $\mathrm{RCC}$ arch dam, in $5^{\text {th }}$ International Symposium on Roller Compacted Concrete Dam, Guiyang, China, 577-581.

Qiuhua, C. 2003. New design method of RCC high arch dam, in Berga, L. (Ed.). The Proceedings of the Fourth International Symposium on Roller Compacted Concrete Dams, Madrid, Spain. Taylor \& Francis: 427-430.

Santurjian, O.; Kolarow, L. 1996. A spatial FEM model of thermal stress state of concrete blocks with creep consideration, Computers \& Structures 58(3): 563-574. http://dx.doi.org/10.1016/0045-7949(95)00156-B

Saetta, A.; Scotta, R.; Vitaliani, R. 1995. Stress analysis of concrete structures subjected to variable thermal loads, Journal of Structural Engineering 121(3): 446-457. http://dx.doi.org/10.1061/(ASCE)0733-9445(1995)121: 3(446)

Sergerlind, L. J. 1984. Applied finite element analysis. 2nd edition. New York: John Wiley and Sons.

Shuping, H.; Ping, H.; Yaozhen, Y.; Baoying, D.; Ping, Y. 1999. The emulation analysis of thermal stresses on RCC arch dams, in International Symposium on Roller Compacted Concrete, China, 482-491.

The consalting Eng. Mahab Ghods- Akerz. 1995. Transmitals of the Karun III Dam Report Design of Dam.

Thelandersson, S. 1987. Modeling of combined thermal and mechanical action in concrete, Journal of Engineering Mechanics 113(6): 813-906. http://dx.doi.org/10.1061/ (ASCE)0733-9399(1987)113:6(893)

Wang, H.; Song, Y. 2008. Behavior of dam concrete under biaxial compression-tension and triaxial compressioncompression-tension stresses, Frontiers of Architecture and Civil Engineering in China 2(4): 323-328. http://dx.doi.org/10.1007/s11709-008-0043-5

$\mathrm{Wu}$, Y.; Luna, R. 2001. Numerical implementation of temperature and creep in mass concrete, Finite elements in analysis and design 37(2): 97-106. http://dx.doi.org/10.1016/S0168-874X(00)00022-6

Xie, H.; Chen, Y. 2005. Influence of the different pipe cooling scheme on temperature distribution in RCC arch dams, Communications in Numerical Methods in Engineering 21(12): 769-778. http://dx.doi.org/10.1002/cnm.793

US Army Corps of Engineers. 2006. Roller-Compacted Concrete. EM 1110-2-2006. Washington, DC.

Zdiri, M.; Ouezdou, M. B.; Néji, J. 2008. Theoretical and experimental study of roller-compacted concrete strength, Magazine of Concrete Research 60(7): 469-474. http://dx.doi.org/10.1680/macr.2007.00002

Zhang, M. L. 1995. Study on structural treatment, stress and stability of roller compacted concrete gravity dam: Master's Thesis. Tsinghua University, Beijing, China.

Zhang, X.; Li, S.; Chen, Y.; Chai, J. 2009. The development and verification of relocating mesh method for the computation of temperature field of RCC dam, Advances in Engineering Software 40(11): 1119-1123. http://dx.doi.org/10.1016/j.advengsoft.2009.05.006

Zhiqi, H.; Huifen, Z.; Jianping, H. ; Yirui, Z. 2007. Simulation analysis on thermal stress of Longtan RCC gravity dam, in Jinsheng, J.; Berga, L.; Guoxin, Z.; Gaixin, C.; Cuiying, Z. (Eds.). New Progress on Roller Compacted Concrete Dams, Guiyang, China, 551-556.

Aeid Ali ABDULRAZEG completed his PhD study at the Universiti of Putra Malaysia. He is currently lecturer at the civil engineering department of Omar Al Mukhtar University. His main area of interest is the finite element analysis of complex structures.

Jamaloddin NOORZAEI completed his PhD study at the University of Roorkee, India. His research interests include computational techniques in civil engineering applications especially those related to structural engineering, soil-structure interaction and earthquake engineering. He was Professor and Head of the Structural Engineering Research group at the Universiti Putra Malaysia (UPM).

Mohamed Saleh JAAFAR obtained his PhD from the University of Sheffield. Currently Professor and Deputy Vice Chancellor of Universiti of Putra Malaysia. His research interests include concrete and prestressed concrete structures, high performance concrete and structural conditions assessment.

Parvin KHANEHZAEI obtained her MSc degree from the Universiti of Putra Malaysia. She is currently a PhD candidate at the same University. Her main area of interest is soil-structure interaction and structural engineering.

Thamer Ahmed MOHAMED completed his PhD study at the Universiti Putra Malaysia, Malaysia. Currently Professor of the Faculty of Engineering UPM, Malaysia. His research interests include hydraulic and hydrologic modeling, sediment transport, urban drainage, groundwater modeling. 